ORIGINAL ARTICLE

\title{
Disruption of the gene Euchromatin Histone Methyl Transferase1 (Eu-HMTase 1) is associated with the 9q34 subtelomeric deletion syndrome
}

\author{
T Kleefstra, M Smidt, M J G Banning, A R Oudakker, H Van Esch, A P M de Brouwer, W Nillesen, \\ E A Sistermans, B C J Hamel, D de Bruijn, J-P Fryns, H G Yntema, H G Brunner, B B A de Vries, \\ $\mathrm{H}$ van Bokhoven
}

J Med Genet 2005;42:299-306. doi: 10.1136/img.2004.028464

Background: A new syndrome has been recognised following thorough analysis of patients with a terminal submicroscopic subtelomeric deletion of chromosome 9q. These have in common severe mental retardation, hypotonia, brachycephaly, flat face with hypertelorism, synophrys, anteverted nares, thickened lower lip, carp mouth with macroglossia, and conotruncal heart defects. The minimum critical region responsible for this $9 q$ subtelomeric deletion syndrome $(9 q-)$ is approximately $1.2 \mathrm{Mb}$ and encompasses at least 14 genes.

See end of article for authors' affiliations Objective: To characterise the breakpoints of a de novo balanced translocation $t(X ; 9)(p 11.23 ; q 34.3)$ in a mentally retarded female patient with clinical features similar to the $9 q-$ syndrome.

Correspondence to: Results: Sequence analysis of the break points showed that the translocation was fully balanced and only one gene on chromosome 9 was disrupted - Euchromatin Histone Methyl Transferasel (Eu-HMTase 1)encoding a histone H3 lysine 9 methyltransferase (H3-K9 HMTase). This indicates that haploinsufficiency Dr Hans van Bokhoven Department of Human Genetics 417, UMC Nijmegen, PÓ Box 9101, $6500 \mathrm{HB}$ Nijmegen, Netherlands; h.vanbokhoven@antrg. umen.nl of Eu-HMTase 1 is responsible for the 9q submicroscopic subtelomeric deletion syndrome. This observation was further supported by the spatio-temporal expression of the gene. Using tissue in situ hybridisation studies in mouse embryos and adult brain, Eu-HMTasel was shown to be expressed in the developing nervous system and in specific peripheral tissues. While expression is selectively downregulated in adult brain, substantial expression is retained in the olfactory bulb, anterior/ventral lateral ventricular wall, and hippocampus and weakly in the piriform cortex.

Received in revised form 29 November 2004 Accepted for publication 1 December 2004 Conclusions: The expression pattern of this gene suggests a role in the CNS development and function, which is in line with the severe mental retardation and behaviour problems in patients who lack one copy of the gene.

$\mathrm{S}$ ubmicroscopic telomeric deletions account for about $5 \%$ of the patients with unexplained mental retardation..$^{1-3}$ This figure is dependent on the patient selection used for studying such aberrations, and ranges from $0.5 \%$ in mild mental retardation to $7.4 \%$ in children with moderate to severe retardation. ${ }^{4}$ Some submicroscopic telomeric deletions are associated with a specific phenotype, such as $1 p-, 4 p-$, $5 p-, 9 p-, 18 p-$, and $17 p-.^{23}$ For most subtelomeric deletions a specific phenotype has not yet been defined, mainly because of the paucity of reported cases. The $9 \mathrm{q} 34.3$ deletion is emerging as one of the more common telomeric deletions and the phenotype is gradually becoming better defined.

Up to now, 22 patients have been reported with a submicroscopic subtelomeric deletion of 9q. ${ }^{24-11}$ The phenotypic features commonly seen in these patients are severe mental retardation, hypotonia, microcephaly, flat face with hypertelorism, synophrys, short nose with anteverted nares, thickened lower lip and carp mouth with tongue protrusion, and conotruncal heart defects. Less frequently observed features are obesity, hearing loss, urogenital abnormalities, and behavioural problems. Stewart et $a l^{8}$ defined the critical chromosomal region responsible for this phenotype by mapping the deletion end points in 12 patients with a subtelomeric deletion of chromosome 9qter. This minimum critical region is approximately $1.2 \mathrm{Mb}$, encompassing at least 14 genes or transcripts, and it is suggested that haploinsufficiency of one or more genes within this region most probably accounts for the $9 q-$ syndrome.

We have previously reported the characterisation of the breakpoints of a de novo balanced translocation $\mathrm{t}(\mathrm{X} ; 9)(\mathrm{p} 11.23 ; \mathrm{q} 34.3)$ present in a female patient with severe mental retardation. ${ }^{12}$ The translocation was found to be completely balanced at the DNA level and disrupted the ZNF81 gene on the $X$ chromosome, while on chromosome 9 the break point disrupted the Eu-HMTasel gene. The ZNF81 gene was subsequently screened for mutations in a cohort of over 300 male patients with $X$ linked mental retardation. A missense mutation in the ZNF81 gene was identified in a linked family with mild non-specific mental retardation. ${ }^{12}$ However, the non-syndromic phenotype in this family is clearly different from that of the translocation patient, indicating that the disruption of ZNF81 is not causative for the severe clinical features in this patient.

In this paper we report a careful evaluation of the clinical presentation of the $t(X ; 9)$ patient, which revealed a striking phenotypic overlap with the $9 \mathrm{q}-$ syndrome. The chromosome 9 breakpoint in this patient disrupts the Eu-HMTasel gene, which precisely maps to the common deletion region found in the $9 \mathrm{q}-$ syndrome. The specific disruption of $E \mathcal{E}$ HMTasel suggest that haploinsufficiency of this gene is responsible for the larger part of the $9 \mathrm{q}-$ phenotype.

Abbreviations: ISH, in situ hybridisation; MLPA, multiplex ligation dependent probe amplification 

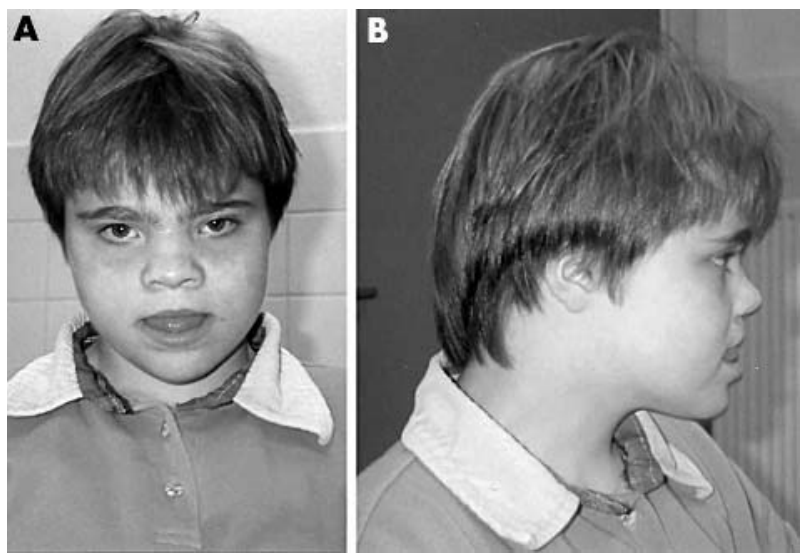

Figure 1 The index patient with a disruption of Eu-HMTase 1 at age 11 . Note brachycephaly, flattened face, upward slanting of palpebral fissures, hypertelorism, synophrys, broad nasal bridge, anteverted nares, protrusion of the tongue, thickened lower lip, and pointed chin. (Informed consent for publication of the clinical pictures has been obtained.)

\section{METHODS \\ Subjects}

Index patient

The index patient had been referred to our department for genetic diagnosis. Routine cytogenetic studies revealed a karyotype that showed a translocation $\mathrm{t}(\mathrm{X} ; 9)(\mathrm{p} 11.2 ; \mathrm{q} 34.3)$. This translocation appeared to be de novo because both parents had a normal karyotype.

\section{Patient panel}

To search for aberrations we selected 37 mentally retarded patients with a normal karyotype but with facial features seen in the $9 q-$ syndrome and previously screened routinely for submicroscopic telomeric deletions within our department. Genomic DNA of each patient was isolated using standard procedures. ${ }^{13}$

\section{Multiplex ligation dependent probe amplification}

A specifically designed set of probes for testing for subtelomeric chromosomal imbalances-SALSA P036 human telomere test kit (MRC-Holland, Amsterdam, Netherlands) was used for subtelomere screening ${ }^{14}$ and included one probe in the MRPL41 gene at 9q34. In addition, a specifically designed probe set including synthetic probes for the $9 \mathrm{q}$ subtelomeric region was developed. Probe preparation has been described previously (see electronic database information). The multiplex ligation dependent probe amplification (MLPA) mix contained two probes for CACNAIB and two for Eu-HMTase1. The full sequences of these probes are available on request.

MLPA analysis was carried out for all 37 selected patients using standard kits, as described by Schouten et al ${ }^{15}$ with minor modifications. Briefly, 200-400 ng DNA was diluted with milliQ to $8 \mu \mathrm{l}$ and heated at $98^{\circ} \mathrm{C}$ for five minutes (GeneAmp PCR System 9700, Applied Biosystems, Foster City, California, USA). The probe mix ( $1.5 \mu$ l per sample) was mixed 1:1 with a salt solution ( $1.5 \mathrm{M} \mathrm{KCl}, 300 \mathrm{mM}$ Tris- $\mathrm{HCl}$ $\mathrm{pH} 8.5,1 \mathrm{mM}$ EDTA) and samples were heated for one minute at $95^{\circ} \mathrm{C}$ and incubated overnight at $60^{\circ} \mathrm{C}$. Next the Ligation-65 mix (MRC Holland) was added and incubated for 15 minutes at $54^{\circ} \mathrm{C}$. Ligase- 65 was inactivated by heating at $98^{\circ} \mathrm{C}$ for one minute. The ligation products were amplified by polymerase chain reaction (PCR) using the common primer set with the 6-FAM label distributed by the supplier. Amplification products were identified and quantified by capillary electrophoresis on an ABI 3100 genetic analyser, using Genescan Analysis (version 3.7) and Genotyper software, all from Applied Biosystems. When synthetic probes were used, they were first diluted to a concentration of $1 \mu \mathrm{M}$. A synthetic probe mix was made of $1 \mu \mathrm{l}$ of each diluted primer and the end volume was adjusted to $250 \mu \mathrm{l}$ with TE buffer. For each reaction, $0.5 \mu \mathrm{l}$ of this mix was added to $1.5 \mu \mathrm{l}$ of the SALSA P036 kit and reactions were carried out as described above.

\section{Mutation screening}

The entire coding region of the Eu-HMTasel gene was sequenced in 15 of the 37 selected patients using genomic DNA as a template. Primers were designed to amplify all the 25 exons of the gene as well as five alternative exons in splice variants. Primer sequences and PCR conditions are available upon request. PCR products were directly sequenced after purification with a Qiagen PCR purification kit (Qiagen Inc, Valencia, California, USA), on an Applied Biosystems 3730 automated sequencer using the same primers as in the PCR.

\section{Expression studies}

Mouse Eu-HMTase 1 expression pattern

With the expressed sequence tag (EST) information contained in the NCBI unigene database, an (in silico) expression pattern of the Eu-HMTasel gene was generated. All ESTs in the Eu-HMTasel unigene cluster (Mm.24176), and their associated dbEST library IDs (LIDs), were re-clustered according to the tissues from which the libraries originated. A listing of the tissues used for all EST libraries was collected from the NCBI Unified Library Database (UNILIB).

\section{Tissue in situ hybridisation}

A 834 bp probe was developed by selecting a primer pair with T3 and T7 stretches (5' -taaccctcactaaagggagatgtcctaatgttcagtaatgg- $3^{\prime}$ and $5^{\prime}$ - taatacgactcactatagggccaagtgtcggcactcaagc$\left.3^{\prime}\right)$ that allowed the specific amplification of the $3^{\prime}$ UTR of the mouse orthologue of Eu-HMTasel. Sense and antisense labelled cDNA probes were developed by using T7 and T3 RNA polymerase, respectively. The in situ hybridisation (ISH) was carried out according to the procedures described by Smidt et al, ${ }^{16}$ on embryos of stage E14.5 and E16.5 and on adult brain, to evaluate the expression pattern.

\section{RESULTS}

\section{$9 q-$ phenotype in a patient with a} $t(X ; 9)(p 11.2 ; q 34.3)$

The propositus is a white girl born after 37 weeks gestation, with a birth weight of $3100 \mathrm{~g}$ (25th centile) and a birth length of $49 \mathrm{~cm}$ (25th centile). Pregnancy and delivery were uneventful. She was the second daughter of healthy, nonconsanguineous parents. In the neonatal period hypotonia and feeding problems were present. The anterior fontanel was enlarged and closed at the age of two years.

At two years, an atrial septal defect type II with pulmonary stenosis was diagnosed, with no haemodynamic consequences at the time.

Psychomotor development was delayed. She walked at the age of $2 \frac{1}{2}$ years, with hardly any speech development. She had a mild to moderate conductive hearing loss on both sides. At four years, she had epileptic seizures with EEG abnormalities, but thereafter no more seizures occurred and the EEG patterns returned to normal. She had severe behavioural problems involving autistic features, aggressiveness, and automutilation. Menarche occurred at 10 years. When we examined her at the age of 11 , she was a non-cooperative, mildly obese girl with apparently normal height and head circumference, brachycephalic skull, and facial dysmorphism (synophrys, upslanting of the palpebral fissures, 
Table 1 Clinical features of patients with $9 q 34.3$ submicroscopic subtelomeric deletion

\begin{tabular}{|c|c|c|c|c|c|c|c|c|}
\hline \multirow[b]{3}{*}{ Symptoms } & \multicolumn{6}{|c|}{ Previous reports } & \multirow{3}{*}{$\begin{array}{l}\text { Total }(\mathrm{N}=22) \\
\text { n }(\%)\end{array}$} & \multirow{3}{*}{$\begin{array}{l}\text { Patient with } \\
\text { disruption of } \\
\text { Eu-HMTase } 1\end{array}$} \\
\hline & \multirow{2}{*}{$\begin{array}{l}\text { Stewart et al, } \\
2004^{8} \\
\text { Total }(n=17)\end{array}$} & \multicolumn{2}{|c|}{ Dawson et al, $2002^{9}$} & \multicolumn{3}{|c|}{ Iwakoshi ef al, $2004^{7}$} & & \\
\hline & & Patient 1 & Patient 2 & Patient 1 & Patient 2 & Patient 3 & & \\
\hline Mental retardation & 16 & + & + & + & + & + & $21(95)$ & + \\
\hline Obesity & 2 & & & & & + & $3(14)$ & + \\
\hline Microcephaly & 14 & + & + & + & + & & $18(82)$ & - \\
\hline Brachycephaly & 8 & & & + & + & + & $11(50)$ & + \\
\hline Flat face & 2 & + & + & + & & & $5(23)$ & + \\
\hline Mid-face hypoplasia & 9 & & & & & & $9(41)$ & + \\
\hline Coarse facies & 8 & & & & & & $8(36)$ & + \\
\hline Hypertelorism & 4 & + & + & + & & & $7(32)$ & + \\
\hline Synophrys & 9 & & + & + & & + & $12(55)$ & + \\
\hline \multicolumn{9}{|l|}{ Downslanting palpebral } \\
\hline fissures & 3 & & & & + & + & $5(23)$ & - \\
\hline Upslanting palpebral fissures & 3 & + & + & & & & $5(23)$ & + \\
\hline Arched eyebrows & 3 & + & + & + & + & + & $8(36)$ & - \\
\hline Short nose & 10 & & & & & & $10(45)$ & + \\
\hline Anteverted nostrils & 10 & + & + & + & + & + & $5(23)$ & + \\
\hline Carp mouth & 12 & + & + & + & + & + & 17 (77) & + \\
\hline \multicolumn{9}{|l|}{ Macroglossia/protruding } \\
\hline tongue & 6 & & & + & + & + & $9(41)$ & + \\
\hline Thick lower lip & 0 & + & + & + & + & + & $5(23)$ & + \\
\hline Pointed chin & 0 & + & + & + & + & + & $5(23)$ & + \\
\hline Malformed ears & 8 & + & + & & & + & $11(50)$ & + \\
\hline Brachydactyly & 3 & & + & & & & $4(18)$ & + \\
\hline Abnormal genitals (males) & 6 & & & & & + & $7(32)$ & - \\
\hline Cardiac anomaly & 6 & & $+(\mathrm{VSD})$ & $+(\mathrm{VSD})$ & $+(\mathrm{VSD})$ & + (murmur) & $10(45)$ & ASD \\
\hline Anal atresia & 1 & & & + & & & $2(9)$ & - \\
\hline Alopecia & 0 & & & + & + & + & $3(14)$ & - \\
\hline Cystic dysplastic kidney & 1 & & & & & & $1(4)$ & - \\
\hline Hydronephrosis & 0 & & & + & + & & $2(9)$ & - \\
\hline Behavioural problems & 2 & & + & & & & $3(14)$ & + \\
\hline Sleep disturbance & 2 & & + & & & & $3(14)$ & + \\
\hline Hearing loss (sensorineural) & 2 & + & & & & & $3(14)$ & + (conductive) \\
\hline Hypotonia & 12 & + & + & + & + & + & 17 (77) & + \\
\hline Seizures & 5 & & + & + & + & & $8(36)$ & + \\
\hline
\end{tabular}

hypertelorism, mid-face hypoplasia, broad nasal bridge, anteverted nares, protrusion of the tongue, thickened lower lip, pointed chin, and small ears (fig 1)).

Table 1 provides a summary of clinical features in 22 previously reported patients with subtelomeric 9q34.3 deletions. $^{7-9}$ Stewart et $a l^{8}$ recently analysed the clinical and molecular characteristics of 17 of these patients. Comparing the characteristics observed in the index patient with the clinical features of the other reported patients, the overlap is striking (table 1). Features commonly seen and present in the index patient are: severe mental retardation, hypotonia, brachycephaly, mid-facial hypoplasia with synophrys and/or arched eyebrows, anteverted nares, carp shape mouth, thick lower lip, tongue protrusion, and heart defects. In addition, behavioural problems, sleep disturbances, and seizures were present in the proband as well.

\section{Eu-HMTase 1 is disrupted by the break point at chromosome 9}

By previous studies, we sequenced the break points of the translocation $\mathrm{t}(\mathrm{X} ; 9)(\mathrm{pl} 1.2 ; \mathrm{q} 34.3)$ and found that the coding sequences of ZNF81 and Eu-HMTasel, respectively, were disrupted. ${ }^{12}$ In fig 2 (panels $\mathrm{A}$ and $\mathrm{B}$ ), we show a schematic drawing of the subtelomeric region of $9 \mathrm{q} 34.3$ and the derivative chromosome 9 with the fusion of the disrupted genes ZNF81 and Eu-HMTase1. Translocations have been reported previously in patients with $9 \mathrm{q}-$ syndrome, but these were always unbalanced and associated with loss of 9qter material. However, sequence analysis of both the X chromosomal and chromosome 9 break points showed that the translocation described here is fully balanced at the genomic level (data not shown). From the der(9) chromosome, a chimeric transcript is produced consisting of part of the ZNF81 gene and an Alu-repeat sequence derived from chromosome 9. This Alu-repeat is in reverse orientation compared with the Eu-HMTasel gene and therefore has the property of inhibiting the expression of the normal $E \mathcal{E}$ HMTasel gene by mechanisms such as RNAi. ${ }^{17}$ To investigate this, we undertook reverse transcriptase polymerase chain reaction (RT-PCR) studies on the Eu-HMTasel gene in lymphoblasts of the proband, but a transcript could still be detected (data not shown).

The finding of a disturbed Eu-HMTasel in the translocation patient and the large clinical overlap of the phenotype of this patient and patients with subtelomeric 9q deletions, as shown in tablel, strongly indicates that haploinsufficiency of Eu-HMTasel is likely to be responsible for the majority of the signs and symptoms.

\section{Tissue in situ hybridisation}

Counting the numbers of Eu-HMTasel derived transcripts in the unigene database showed that Eu-HMTasel is expressed throughout embryonic development, starting as early as the fertilised oocyte (fig 3). High relative expression was also observed in cDNA libraries obtained from neonatal and adult brain, eye, germ cells, and adult cardiac muscle.

In order to obtain a more accurate impression of the spatiotemporal expression of Eu-HMTasel during development, we designed a probe suitable for tissue ISH. This analysis revealed that Eu-HMTasel is expressed in a broad array of structures in the developing mouse (figs 4 and 5). At these stages Eu-HMTasel is expressed in all structures of the central nervous system (CNS). Interestingly, the developing cortex shows a laminar structure at E16.5 indicating that 


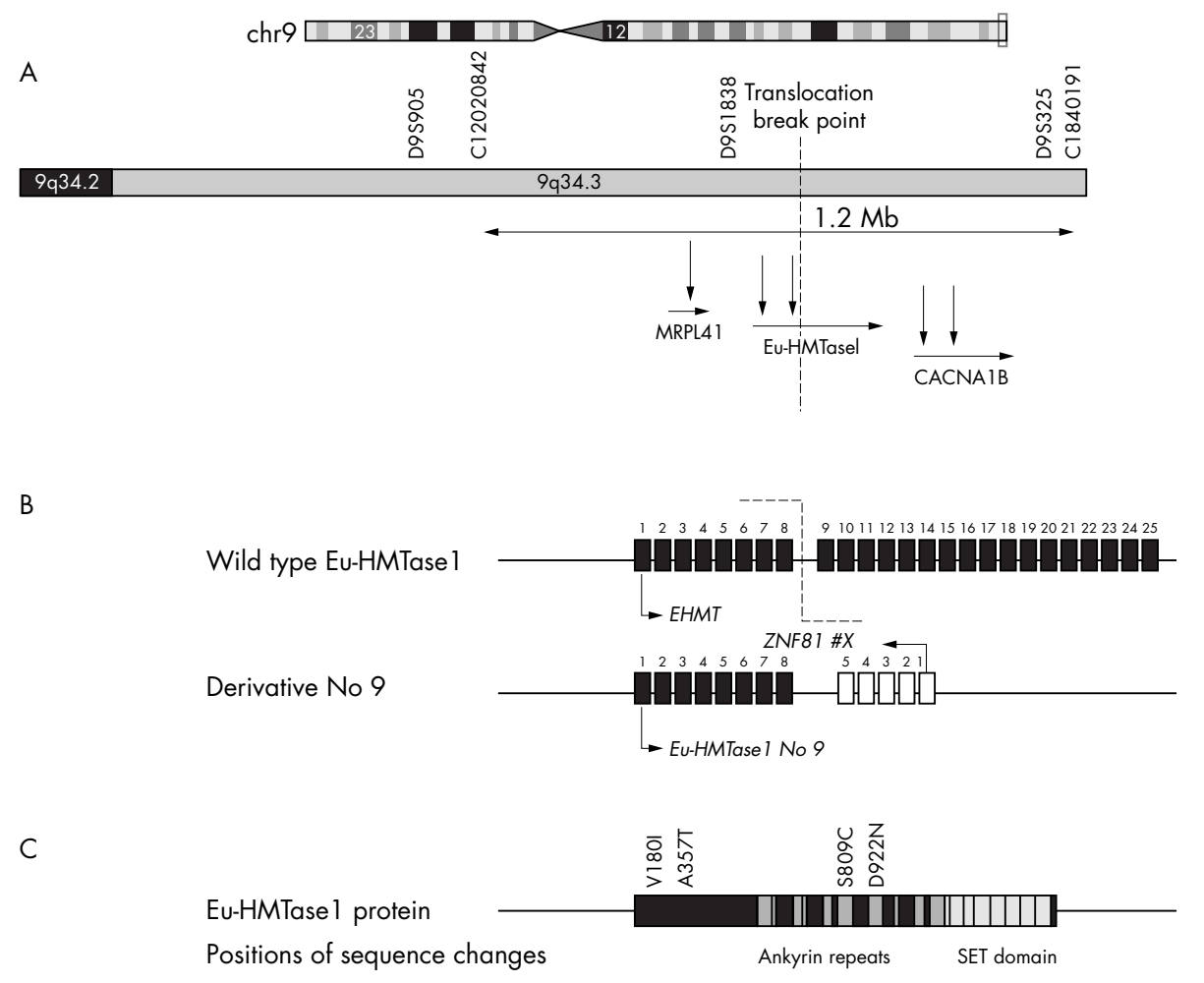

Figure 2 Schematic view of the subtelomeric region of $9 q 34.3$, including the minimum critical region of $1.2 \mathrm{Mb}(\mathrm{A})$, the derivative chromosome 9 (B), and the Eu-HMTasel protein (C). (A) Positions and orientation of the genes MRPL41, Eu-HMTasel, and CACNA1B in the minimum 1.2 Mb critical interval. Vertical arrow heads indicate the positions of the probes used in the MLPA. (B) Schematic diagram (not to scale) indicating the exon-intron structures of ZNF81 and Eu-HMTase 1 relative to the break point region. The break point in Eu-HMTase 1 is situated 11 bp from the 3' end of exon 8, resulting in a derivative chromosome 9 with a fusion of the $5^{\prime}$ end of the gene Eu-HMTase 1 to the $5^{\prime}$ end of the X chromosomal gene ZNF81. The translocation was found to be fully balanced on the genomic level. (C) The positions of the four novel identified polymorphisms in the protein. Note the S809C and D229N which are present in the conserved ankyrin repeats but also identified in one of the two parents of the respective patients.

regulation of this gene occurs in the specific layers. The embryonic expression pattern is restricted in the adult brain to the olfactory bulb, the anterior/ventral ventricular wall, the hippocampus, and the piriform cortex (fig 6). Outside the CNS several tissues express Eu-HMTasel (figs 4 and 5), including the developing nasal epithelium, tongue, thymus, gut, lungs, and kidney.

\section{MLPA analysis and mutation screening}

Haploinsufficiency for the Eu-HMTasel gene in the index patient and in patients with a 9qter deletion causes a strikingly similar phenotype. Therefore, it is likely that microdeletions or other inactivating mutations in the $E \mathcal{E}$ HMTael gene may account for other patients with a similar phenotype but without a demonstrable microscopic deletion. To investigate this, we selected 37 patients with a comparative phenotype for MLPA studies on subtelomeric submicroscopic $9 \mathrm{q}$ deletions, and subsequently carried out mutation analysis of the Eu-HMTasel gene in 15 of them. MLPA probes were selected for the Eu-HMTasel gene and flanking genes MRPL41 and CACNA1B (fig 2A). While MLPA analysis provided clear evidence for monosomy of chromosome 9qter in a previously reported deletion patient, ${ }^{6}$ the selected probes failed to detect any new deletions in the 37 patients whom we selected (data not shown). Direct sequence analysis of the Eu-HMTasel gene in 15 of these patients identified eight sequence variants that were predicted to result in amino acid substitutions in the Eu-HMTasel protein (fig 2C). Four of these were already known in SNP databases and are likely to be polymorphisms (table 2 ). Segregation studies of the other four changes revealed that each of the changes was present in one of the phenotypically normal parents, indicating that these represent polymorphisms as well.

\section{DISCUSSION}

We here describe how a patient with a disruption of EuHMTasel has the same clinical characteristics as are seen in patients with a submicroscopic subtelomeric $9 \mathrm{q}$ deletion $(9 q-)$. This strongly indicates that haploinsufficiency of $E \mathcal{U}$ HMTasel is responsible for the phenotype in this patient as well as for the major part of the $9 q-$ syndrome. Further support for this is provided by a parallel paper in which two patients are reported with a $9 q-$ phenotype and microdeletions that define the critical region encompassing two genes including Eu-HMTase $1 .{ }^{18}$ Our results provided a rationale for mutation screening in patients with a similar phenotype. We carried out MPLA in 37 patients sharing some of the clinical features and sequenced the entire coding region in 15 of them. In none of these patients were Eu-HMTasel abnormalities detected. However, this does not imply that such patients do not exist. The numbers tested here may have been too small to identify additional mutations, and patients with a phenotype similar to that seen in individuals with $9 q-$ syndrome but without chromosomal abnormalities are scarce. To increase the chances of identifying such deletions, we have included the reported Eu-HMTasel probes in the standard MLPA kit that is used for the detection of subtelomeric deletions in mentally retarded patients in our DNA diagnostic services. 


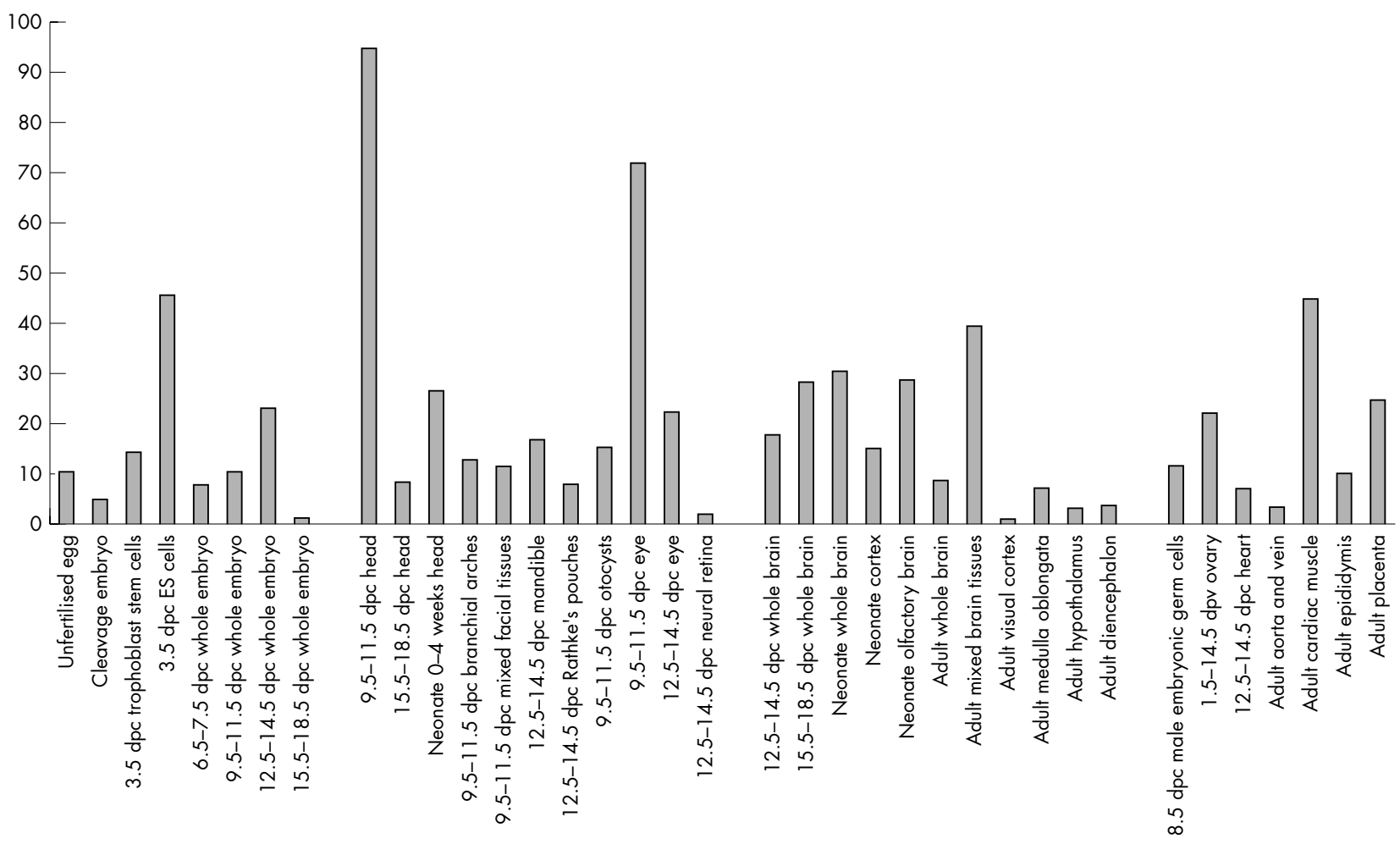

Figure 3 Expression pattern of Eu-HMTase 1 estimated by in silico analysis. The in silico Eu-HMTasel expression pattern in selected mouse tissues generated from EST data in unigene cluster Mm.24176. Expression levels are indicated as numbers of EST sequences per 50000 total ESTs in each tissue.

The phenotypic overlap between the patient with the disrupted Eu-HMTasel gene and the 9q- syndrome is striking (fig 1, table 1). All the major features of the $9 \mathrm{q}-$ syndrome were present in the translocation patient, in addition to some less reported features: behavioural problems, sleep disturbances, and seizures. The only significant exception is
A

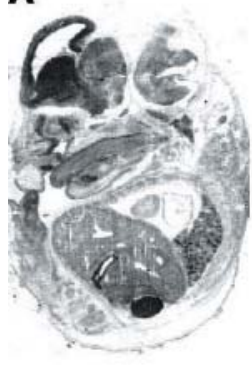

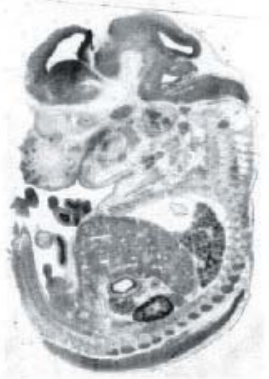
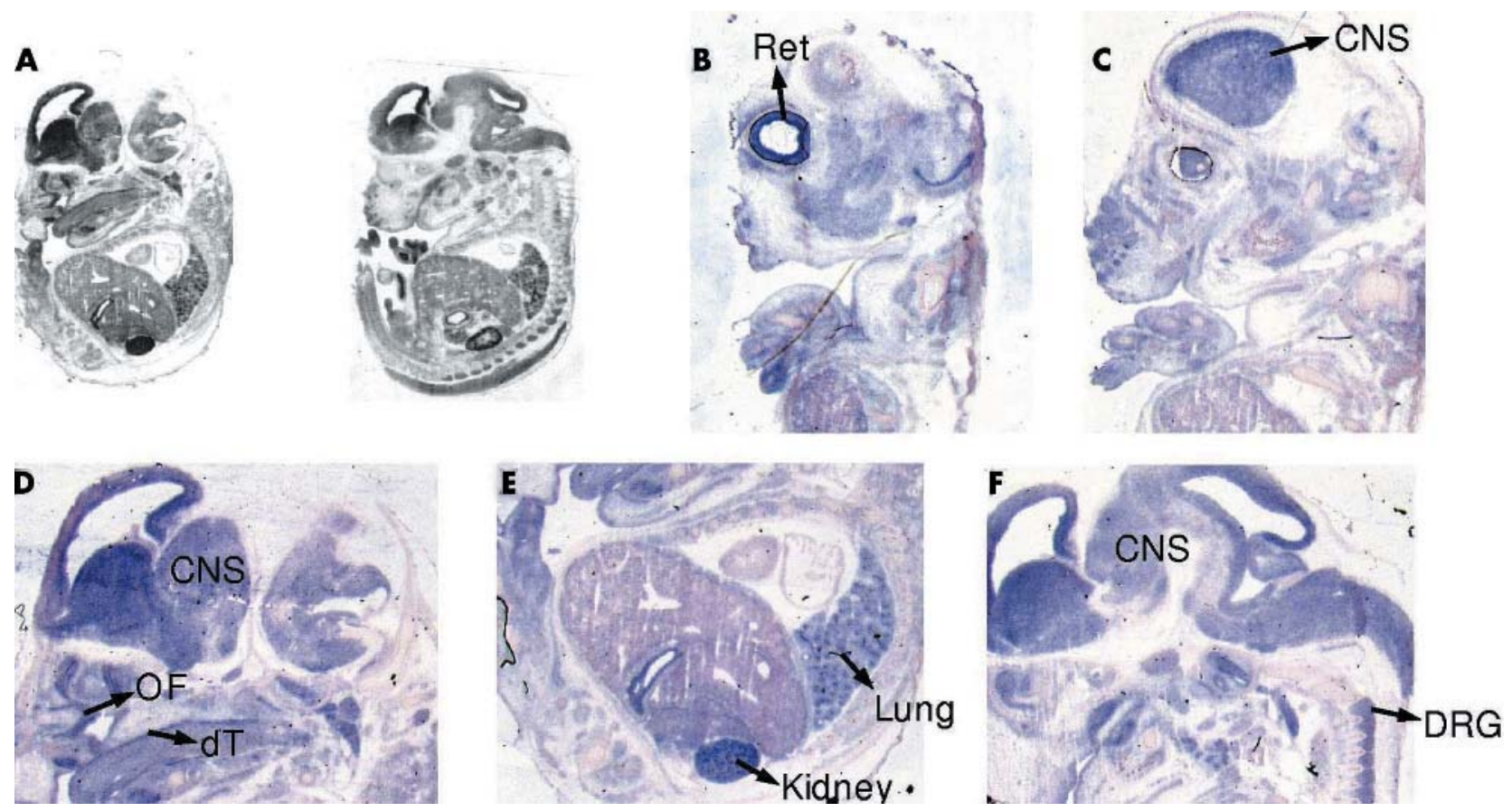

Figure 4 Eu-HMTasel ISH on sagittal sections of a mouse embryo of stage E14.5. (A) Overview of a lateral and medial section through the embryo. (B) Lateral section showing expression in the developing retina (Ret). (C) More medial section showing expression in the lateral part of the forebrain area (CNS). (D) More medial view on the developing head. Expression was indicated in the olfactory epithelium (OF), the dorsal surface of the tongue (dT) and in the tongue itself, and again in the developing nervous system (CNS). (E) Developing body structures. Expression was clearly found in the lung and kidney. (F) Expression in the dorsal root ganglia (DRG) and again in the CNS. 

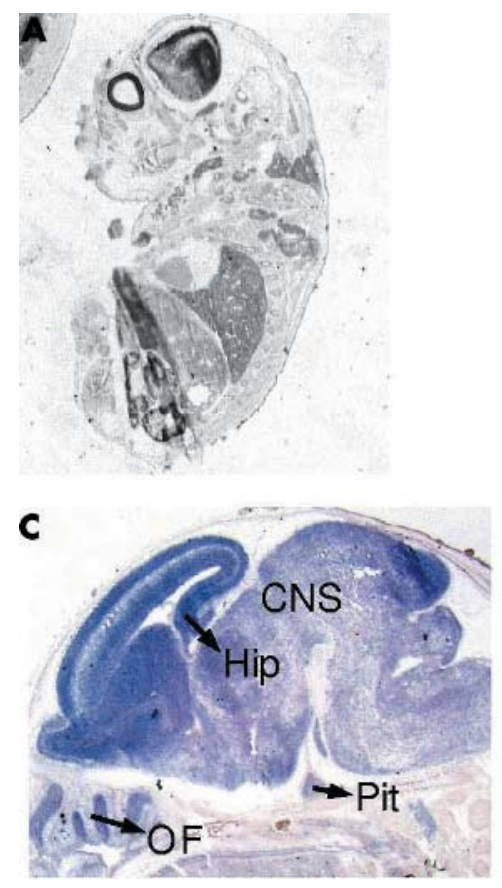
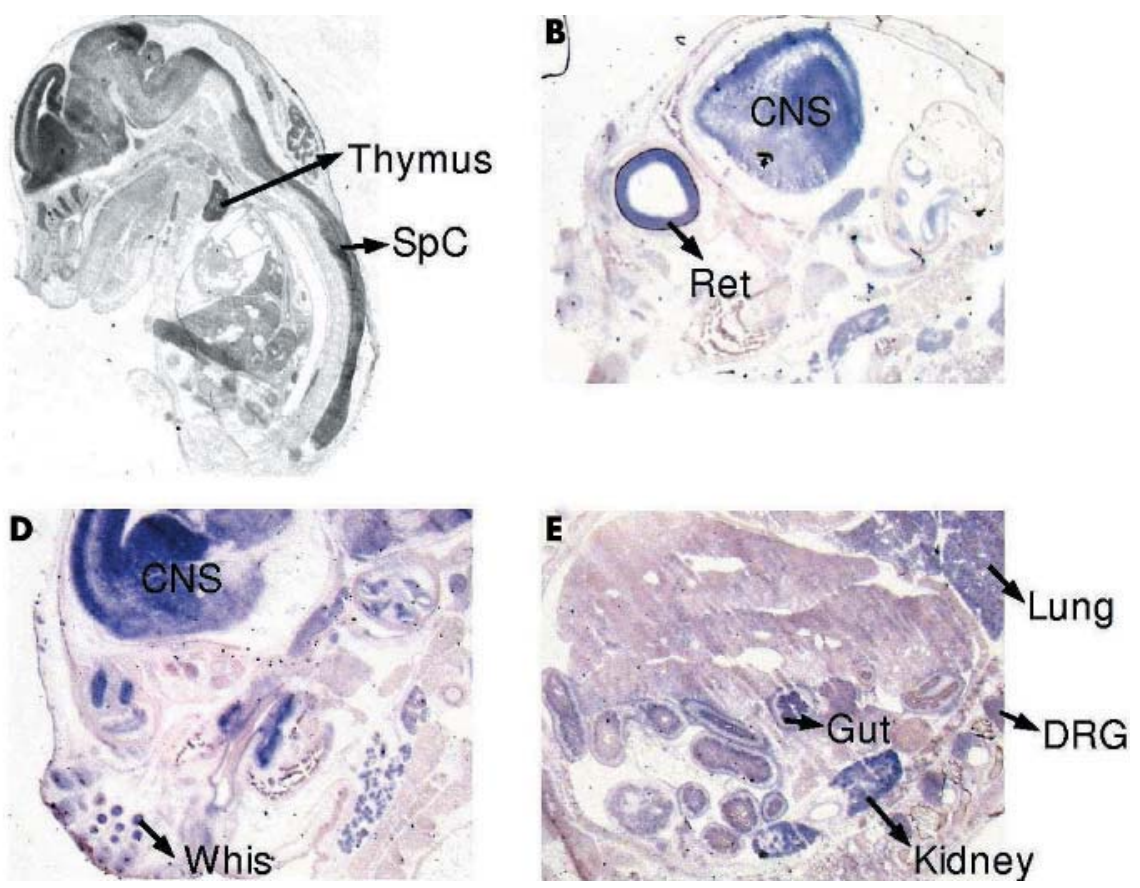

Figure 5 Eu-HMTasel ISH on sagittal sections of a mouse embryo of stage E16.5. (A) Overview of a lateral and medial section through the embryo. The expression in the thymus and spinal cord ( $\mathrm{SpC}$ ) is indicated. (B) Lateral section of the embryo head showing expression in the retina (Ret) and CNS. (C) Expression in the regions of the CNS including the developing hippocampus (Hip); also note the layer formation of the developing cortex. OF, olfactory epithelium; Pit, pituitary. (D) Expression in the developing whiskers (Whis) and CNS. (E) Expression in the lung, dorsal root ganglia (DRG), gut, and kidney.

microcephaly, which is common in $9 q-$ patients ( 18 of 22 cases), but absent in the translocation patient. This may just be a reflection of the clinical variability that characterises $9 \mathrm{q}-$ syndrome patients. Another likely explanation is that the microcephaly in $9 \mathrm{q}-$ syndrome is not caused by haploinsufficiency for the Eu-HMTasel gene, but by deletion of another gene from the subtelomeric region of chromosome 9q. This explanation may also apply to some of the other less frequent clinical features such as soft brittle hair with partial alopecia and urinary tract anomalies.

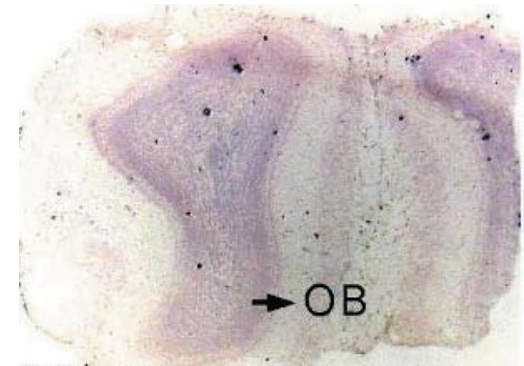

3.5

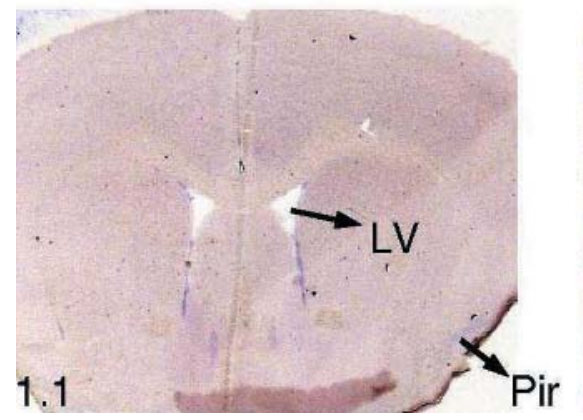

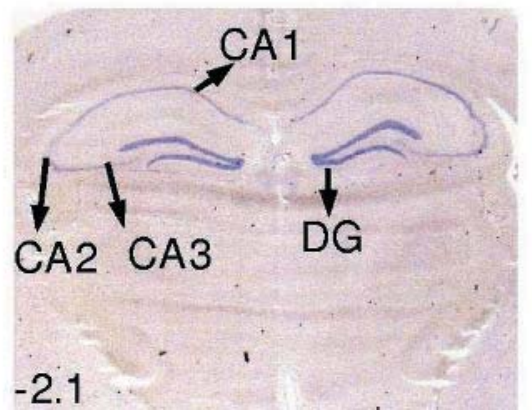

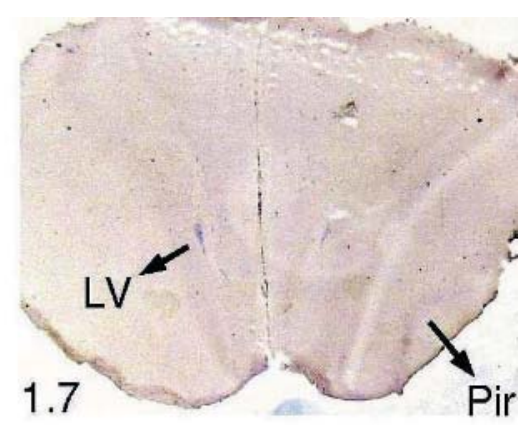

2.8

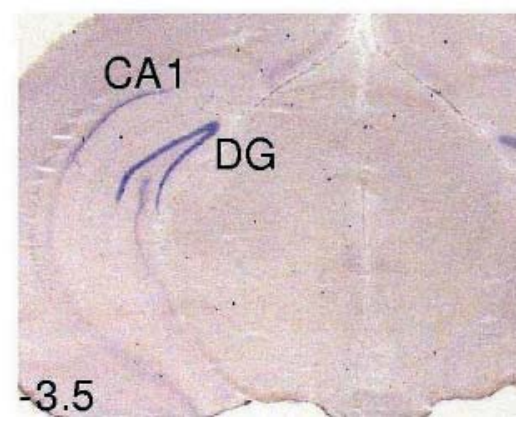

Figure 6 In situ hybridisation on coronal sections of adult mouse brain from rostral to caudal (bregma 3.5 to -3.5 ) using a DIG labelled RNA probe specific for Eu-HMTase 1. In rostral sections expression was detected in the olfactory bulb (OB) and the ventral ventricle wall (LV). More caudal expression was detected in different areas of the hippocampus (CA1, CA2, CA3, DG (dentate gyrus)) and weak in the piriform cortex (Pir). The position of the sections is shown relative to bregma. 
Table 2 Changes found with direct sequencing in the EuHMTasel gene

\begin{tabular}{|c|c|c|c|}
\hline Sequence change & $\begin{array}{l}\text { Amino acid } \\
\text { change }\end{array}$ & Exon & Segregation \\
\hline \multicolumn{4}{|c|}{ Known polymorphisms } \\
\hline c. $347 \mathrm{~T} \rightarrow \mathrm{C}$ & p.L116L & 1 & *NA \\
\hline c. $351 \mathrm{~T} \rightarrow \mathrm{C}$ & p.P117P & 1 & *NA \\
\hline c. $951 \mathrm{G} \rightarrow \mathrm{A}$ & p.S317s & 4 & *NA \\
\hline c. $996 \mathrm{~T} \rightarrow \mathrm{C}$ & p.G332G & 4 & *NA \\
\hline \multicolumn{4}{|l|}{ Novel changes } \\
\hline c. $538 \mathrm{G} \rightarrow \mathrm{A}$ & p.V180I & 1 & Father heterozygote \\
\hline c. $1069 \mathrm{G} \rightarrow \mathrm{A}$ & p.A357T & 4 & $\begin{array}{l}\text { Father and mother } \\
\text { heterozygote }\end{array}$ \\
\hline c. $2426 \mathrm{C} \rightarrow \mathrm{G}$ & p.S809C & 15 & Father heterozygote \\
\hline c. $2764 \mathrm{G} \rightarrow \mathrm{A}$ & p.D922N & 17 & Mother heterozygote \\
\hline
\end{tabular}

According to EST data extracted from electronic databases, Eu-HMTase 1 is abundantly expressed in embryonic stem cells, in brain and eye during embryonic development, in various adult brain tissues, and in adult cardiac muscle. We have shown using ISH that Eu-HMTasel is expressed in a broad array of structures in the developing mouse, whereas in the adult mouse, the expression pattern is confined to a few regions of the brain. This expression pattern of the EuHMTasel supports the hypothesis that this gene is an excellent candidate as a cause of mental retardation and congenital abnormalities. Expression in the adult brain is restricted to specific areas of the olfactory bulb, the anterior/ ventral ventricular wall, the hippocampus, and the piriform cortex. Interestingly, these structures are all known to harbour cell populations with high proliferative potential. ${ }^{19-}$ ${ }^{21}$ As widespread expression of Eu-HMTasel is also observed in embryonic CNS development, it appears that this gene has an important role in proliferation of neuronal precursor cells in neurogenesis. Alternatively, the high expression of the gene in regions containing dividing cells may also point to a role of the Eu-HMTasel protein in mitotic silencing of neuronal precursor cells after cell division. For both of these postulated functions it is of interest that Eu-HMTasel acts as an epigenetic regulator of transcription.

Eu-HMTasel was identified in $2002^{22}$ and was found to be closely related to the G9a protein. Both Eu-HMTasel and G9a are H3-K9 HMTases which are present in euchromatic regions and they form complexes with heterochromatin protein $1(\mathrm{HPl} \gamma)$ and a subset of E2F transcription factors. ${ }^{22}$ The E2F-6 complex preferentially occupies target promoters in $G_{0}$ cells rather than $G_{1}$ cells, suggesting a role in silencing of target genes in quiescent cells. In view of the restricted expression in adult mouse brain it appears likely that EuHMTasel plays an important role in carrying out the epigenetic histone modifications which are needed to transfer a subset of the neuronal precursor cells into the $G_{0}$ phase after cell division. It was shown recently that homozygous mutant mouse embryos with a mutation in G9a die at $8.5 \mathrm{dpc}$ (days post-conception), implying that euchromatin H3-K9 methylation is essential for early embryogenesis. ${ }^{23}$ The findings with ESET, another H3-K9 HMTase, were similar ${ }^{24}$; these investigators reported that ESET-null embryos show peri-implantation lethality. In addition to histone methylation, H3-K9 HMTases also influence DNA methylation. ${ }^{25} 26$ Thus G9a-null embryo stem cells (ES) show altered DNA methylation in the Prader-Willi imprinted region. ${ }^{25}$ Knockout mice for Eu-HMTasel have not been reported to date.

Studies in recent years have revealed that histone methylation plays an important role in modulating chromatin structure and function. ${ }^{27}{ }^{28}$ Histone methylation occurs on arginine and lysine residues at the $\mathrm{N}$-terminal tails of histones $\mathrm{H} 3$ and $\mathrm{H} 4$ and is catalysed by two distinct protein families, the PRMTI and the SET domain containing family. Recently, a third family of histone methyl transferases (HMTases) that target lysine 79 was reported, located in the globular domain of histone H3. ${ }^{29}$ Thus far, six lysine residues located on histones $\mathrm{H} 3$ (lysines 4, 9, 27, 36, and 79) and H4 (lysine 20) have been reported to be sites of methylation. Lysine 9 methylation $(\mathrm{H} 3-\mathrm{K} 9)$ is the best studied owing to its fundamental role in chromatin formation, transcriptional silencing, $\mathrm{X}$ chromosome inactivation. and DNA methylation. ${ }^{30}$

There is a growing number of mental retardation genes that appear to play a role in chromatin remodelling: $M E C P 2$, RSK2, XNP, DNTM 3B, and CBP. ${ }^{31}$ Three of these genes$M E C P 2, R S K 2$, and XNP-are involved in syndromic and nonsyndromic forms of $X$ linked mental retardation (XLMR). Mutations in the MECP2 gene cause RTT syndrome in females, mostly in isolated cases. ${ }^{31}{ }^{32}$ In addition, there are several families in which $M E C P 2$ mutations cause male limited non-specific XLMR. ${ }^{33}{ }^{34}$ The MeCP2 protein is a methyl-CpG-binding protein that forms transcription repression complexes with Sin3a and several histone deacetylases. ${ }^{31356}$ The RSK2 gene is involved in Coffin-Lowry syndrome $^{37}$ and, in one family, in non-specific mental retardation. ${ }^{38}$ The corresponding protein is a ribosomal S6 kinase involved in RAS-MAPK-ERK signalling. In addition, it has been shown that RSK2 can phosphorylate histone $\mathrm{H} 3$ and the CREB binding protein CBP, which in turn acetylates histone H3. ${ }^{39}{ }^{40}$ Mutations in the CBP gene are causative for Rubinstein-Taybi syndrome. ${ }^{41}$ The XNP gene is the third $\mathrm{X}$ chromosomal XLMR gene with a role in chromatin remodelling. Mutations in the XNP gene cause the ATRX syndrome and various other syndromes with overlapping clinical features. ${ }^{42}$ Also, non-specific XLMR has been reported in two families. ${ }^{43}{ }^{44} \mathrm{XNP}$ (X linked nuclear protein) is a member of the Swi/Snf family of RNA helicases. Interaction between the XNP protein and two heterochromatin binding proteins, $\mathrm{HPl}$ and EZH2, is well documented. ${ }^{45}$ Interestingly, two recently identified XLMR genes also encode predicted interactors of HP1, KRAB-ZNF (Krüppel associated box-zinc finger proteins) and the related ZNF41 and ZNF81. ${ }^{12} 46$

The current identification of Eu-HMTasel as the causative gene in yet another mental retardation syndrome strongly suggests that disruption of epigenetic patterns is a common cause of mental retardation and indicates that this type of transcriptional regulation is important in normal brain development.

\section{ELECTRONIC DATABASE INFORMATION}

Accession numbers and URLs for data presented in this report are as follows:

- GenBank, http://www.ncbi.nlm.nih.gov/Genbank/ (for EuHMTasel accession number NM_Q9H9Bl (human) and NM_BC056938 (mouse).

- MRC-Holland, http://www.mrc-holland.com/ (for SALSA P036 Human Telomere Test Kit) MLPA, http://www.mlpa. com/mlpa_protocols.htm

- UCSC Genome Browser (Golden Path), http://genome.ucsc. edu/cgi-bin/ (July 2003 and May 2004 Build)

- NCBI Unified Library Database (UNILIB), http://www. ncbi.nlm.nih.gov/UniGene/clust.cgi

\section{ACKNOWLEDGEMENTS}

This work was supported by grants from ZonMw, grant 940-37-031 (TK) and ZonMw, grant 907-00-058 (BdV), Dutch Brain Foundation, grants 12F04(27)64 and 10F02(2)43 (HY), and an EU grant, QLG3CT-2002-01810 (HvB; EURO-MRX). 


\section{Authors' affiliations}

T Kleefstra, M J G Banning, A R Oudakker, A P M de Brouwer, W Nillesen, E A Sistermans, B C J Hamel, D de Bruijn, H G Yntema, H G Brunner, B B A de Vries, H van Bokhoven, Department of Human Genetics, University Medical Centre St Radboud, Nijmegen, Netherlands M Smidt, Rudolf Magnus Institute of Neuroscience, University Medical Centre Utrecht, Utrecht, Netherlands

H Van Esch, J-P Fryns, Centre for Human Genetics, University Hospital Leuven, Leuven, Belgium

Competing interests: none declared

\section{REFERENCES}

1 Slavotinek A, Rosenberg M, Knight S, Gaunt L, Fergusson W, Killoran C, Clayton-Smith J, Kingston H, Campbell RH, Flint J, Donnai D, Biesecker L. Screening for submicroscopic chromosome rearrangements in children with idiopathic mental retardation using microsatellite markers for the chromosome telomeres. J Med Genet 1999:36:405-11.

2 de Vries BB, Winter R, Schinzel A, Ravenswaaij-Arts C. Telomeres: a diagnosis at the end of the chromosomes. J Med Genet 2003;40:385-98.

3 Schinzel A. Catalogue of unbalanced chromosome aberrations in man, 2nd ed. Berlin: deGruyter, 2001.

4 Knight SJ, Regan R, Nicod A, Horsley SW, Kearney L, Homfray T, Winter RM, Bolton $\mathrm{P}$, Flint J. Subtle chromosomal rearrangements in children with unexplained mental retardation. Lancet 1999;354:1676-81.

5 Cormier-Daire V, Molinari F, Rio M, Raoul O, de Blois MC, Romana S, Vekemans M, Munnich A, Colleaux L. Cryptic terminal deletion of chromosome 9q34: a novel cause of syndromic obesity in childhood? J Med Genet 2003;40:300-3.

6 Anderlid BM, Schoumans J, Anneren G, Sahlen S, Kyllerman M, Vujic M, Hagberg B, Blennow E, Nordenskjold M. Subtelomeric rearrangements detected in patients with idiopathic mental retardation. Am J Med Genet 2002;107:275-84.

7 Iwakoshi M, Okamoto N, Harada N, Nakamura T, Yamamori S, Fujita H, Niikawa N, Matsumoto N. 9q34.3 deletion syndrome in three unrelated children. Am J Med Genet 2004;126A:278-83.

8 Stewart DR, Huang A, Faravelli F, Anderlid BM, Medne L, Ciprero K, Kaur M, Rossi E, Tenconi R, Nordenskjold M, Gripp KW, Nicholson L, Meschino WS, Capua E, Quarrell OW, Flint J, Irons M, Giampietro PF, Schowalter DB, Zaleski CA, Malacarne M, Zackai EH, Spinner NB, Krantz ID. Subtelomeric deletions of chromosome 9q: A novel microdeletion syndrome. Am J Med Genet 2004:128A:340-51.

9 Dawson AJ, Putnam S, Schultz J, Riordan D, Prasad C, Greenberg CR, Chodirker BN, Mhanni AA, Chudley AE. Cryptic chromosome rearrangements detected by subtelomere assay in patients with mental retardation and dysmorphic features. Clin Genet 2002;62:488-94.

10 Rossi E, Piccini F, Zollino M, Neri G, Caselli D, Tenconi R, Castellan C, Carrozzo R, Danesino C, Zuffardi O, Ragusa A, Castiglia L, Galesi O, Greco D, Romano C, Pierluigi M, Perfumo C, Di Rocco M, Faravelli F, Dagna BF, Bonaglia M, Bedeschi M, Borgatti R. Cryptic telomeric rearrangements in subjects with mental retardation associated with dysmorphism and congenital malformations. J Med Genet 2001;38:417-20.

11 Fauth C, Zhang H, Harabacz S, Brown J, Saracoglu K, Lederer G, Rittinger O Rost I, Eils R, Kearney L, Speicher MR. A new strategy for the detection of subtelomeric rearrangements. Hum Genet 2001;109:576-83.

12 Kleefstra T, Yntema HG, Oudakker AR, Banning MJ, Kalscheuer VM, Chelly J, Moraine C, Ropers HH, Fryns JP, Janssen IM, Sistermans EA, Nillesen WN, de Vries LB, Hamel BC, van Bokhoven H. Zinc finger 81 (ZNF81) mutations associated with X-linked mental retardation. J Med Genet 2004:41:394-9.

13 Miller SA, Dykes DD, Polesky HF. A simple salting out procedure for extracting DNA from human nucleated cells. Nucleic Acids Res 1988;16:1215.

14 Koolen DA, Nillesen WM, Versteeg MH, Merkx GF, Knoers NV, Kets M, Vermeer S, van Ravenswaaij CM, de Kovel CG, Brunner HG, Smeets D, de Vries BB, Sistermans EA. Screening for subtelomeric rearrangements in 210 patients with unexplained mental retardation using multiplex ligationdependent probe amplification. J Med Genet 2004;41:892-9.

15 Schouten JP, McElgunn CJ, Waaijer R, Zwijnenburg D, Diepvens F, Pals G. Relative quantification of 40 nucleic acid sequences by multiplex ligationdependent probe amplification. Nucleic Acids Res 2002;30:e57.

16 Smidt MP, van Schaick HS, Lanctot C, Tremblay JJ, Cox JJ, van der Kleii AA Wolterink G, Drouin J, Burbach JP. A homeodomain gene Ptx3 has highly restricted brain expression in mesencephalic dopaminergic neurons. Proc Natl Acad Sci USA 1997:94:13305-10

17 Osato N, Yamada H, Satoh K, Ooka H, Yamamoto M, Suzuki K, Kawai J, Carninci P, Ohtomo Y, Murakami K, Matsubara K, Kikuchi S, Hayashizaki Y. Antisense transcripts with rice full-length cDNAs. Genome Biol 2003;5:R5

18 Yatsenko SA, Cheung SW, Scott DA, et al. Deletion9q34. 3 syndrome: genotype-phenotype correlations and an extended deletion in a patient with Opitz C trigonencephaly. J Med Genet 2005:42:328-35.

19 Bernier PJ, Bedard A, Vinet J, Levesque M, Parent A. Newly generated neurons in the amygdala and adjoining cortex of adult primates. Proc Natl Acad Sci USA 2002;99:11464-9.
20 Bedard A, Parent A. Evidence of newly generated neurons in the human olfactory bulb. Brain Res Dev Brain Res 2004;151:159-68.

21 Prickaerts J, Koopmans G, Blokland A, Scheepens A. Learning and adult neurogenesis: survival with or without proliferation? Neurobiol Learn Mem 2004:81:1-11

22 Ogawa H, Ishiguro K, Gaubatz S, Livingston DM, Nakatani Y. A complex with chromatin modifiers that occupies E2F- and Myc-responsive genes in G0 cells. Science 2002;296:1132-6.

23 Tachibana M, Sugimoto K, Nozaki M, Ueda J, Ohta T, Ohki M, Fukuda M, Takeda N, Niida H, Kato H, Shinkai Y. G9a histone methyltransferase plays a dominant role in euchromatic histone $\mathrm{H} 3$ lysine 9 methylation and is essential for early embryogenesis. Genes Dev 2002;16:1779-91.

24 Dodge JE, Kang YK, Beppu H, Lei H, Li E. Histone H3-K9 methyltransferase ESET is essential for early development. Mol Cell Biol 2004;24:2478-86.

25 Xin Z, Tachibana M, Guggiari M, Heard E, Shinkai Y, Wagstaff J. Role of histone methyltransferase G9a in CpG methylation of the Prader-Willi syndrome imprinting center. J Biol Chem 2003;278:14996-5000.

26 Tamaru H, Selker EU. A histone H3 methyltransferase controls DNA methylation in Neurospora crassa. Nature 2001;414:277-83.

27 Lachner M, O'Sullivan RJ, Jenuwein T. An epigenetic road map for histone lysine methylation. J Cell Sci 2003;116:2117-24.

28 Lachner $M$, Jenuwein T. The many faces of histone lysine methylation. Curr Opin Cell Biol 2002;14:286-98

29 Feng Q, Wang H, Ng HH, Erdjument-Bromage H, Tempst P, Struhl K, Zhang Y. Methylation of $\mathrm{H} 3$-lysine 79 is mediated by a new family of HMTases without a SET domain. Curr Biol 2002;12:1052-8.

30 Richards EJ, Elgin SC. Epigenetic codes for heterochromatin formation and silencing: rounding up the usual suspects. Cell 2002;108:489-500.

31 Ausio J, Levin DB, De Amorim GV, Bakker S, Macleod PM. Syndromes of disordered chromatin remodeling. Clin Genet 2003;64:83-95.

32 Amir RE, Van den Veyver IB, Wan M, Tran CQ, Francke U, Zoghbi HY. Rett syndrome is caused by mutations in X-linked $M E C P 2$, encoding methyl-CpGbinding protein 2. Nat Genet 1999;23:185-8.

33 Couvert P, Bienvenu T, Aquaviva C, Poirier K, Moraine C, Gendrot C, Verloes A, Andres C, Le Fevre AC, Souville I, Steffann J, des Portes V Ropers H-H, Yntema HG, Fryns J-P, Briault S, Chelly J, Cherif B. MECP2 is highly mutated in X-linked mental retardation. Hum Mol Genet 2001;10:941-6.

34 Yntema HG, Oudakker AR, Kleefstra T, Hamel BCJ, van Bokhoven H, Chelly J, Kalscheuer VM, Fryns J-P, Raynaud M, Moizard M-P, Moraine C. In frame deletion in MECP2 causes mild nonspecific mental retardation. Am J Med Genet 2002;107:81-3.

35 Nan X, Ng H-H, Johnson CA, Laherty CD, Turner BM, Eisenman RN, Bird A. Transcriptional repression by the methyl-CpG-binding protein MeCP2 involves a histone deacetylase complex. Nature 1998;393:386-9.

36 Jones PL, Veenstra GJ, Wade PA, Vermaak D, Kass SU, Landsberger N, Strouboulis J, Wolffe AP. Methylated DNA and MeCP2 recruit histone deacetylase to repress transcription. Nat Genet 1998;19:187-91.

37 Trivier E, De Cesare D, Jacquot S, Pannetier S, Zackai E, Young I, Mandel J-L, Sassone-Corsi P, Hanauer A. Mutations in the kinase Rsk-2 associated with Coffin-Lowry syndrome. Nature 1996;384:567-70

38 Merienne K, Jacquot S, Pannetier S, Zeniou M, Bankier A, Gecz J, Mandel J-L, Mulley J, Sassone-Corsi P, Hanauer A. A missense mutation in RPS6KA3 (RSK2) responsible for non-specific mental retardation. Nat Genet 1999;22:13-14.

39 Sassone-Corsi P, Mizzen CA, Cheung P, Crosio C, Monaco L, Jacquot S, Hanaver A, Allis CD. Requirement of Rsk-2 for epidermal growth factoractivated phosphorylation of histone H3. Science 1999; 285:886-91.

40 Merienne K, Pannetier S, Harel-Bellan A, Sassone-Corsi P. Mitogen-regulated RSK2-CBP interaction controls their kinase and acetylase activities. Mol Cell Biol 2001;21:7089-96.

41 Petrij F, Giles RH, Dauwerse HG, Saris JJ, Hennekam RC, Masuno M, Tommerup N, van Ommen GJ, Goodman RH, Peters DJ. Rubinstein-Taybi syndrome caused by mutations in the transcriptional co- activator CBP. Nature 1995;376:348-51.

42 Gibbons RJ, Higgs DR. Molecular-clinical spectrum of the ATR-X syndrome. Am J Med Genet 2000;97:204-12.

43 Guerrini R, Shanahan JL, Carrozzo R, Bonanni P, Higgs DR, Gibbons RJ. A nonsense mutation of the ATRX gene causing mild mental retardation and epilepsy. Ann Neurol 2000;47:117-21.

44 Yntema HG, Poppelaars FA, Derksen E, Oudakker AR, van Roosmalen T Jacobs A, Obbema H, Brunner HG, Hamel BC, van Bokhoven H. Expanding phenotype of XNP mutations: mild to moderate mental retardation. Am J Med Genet 2002;1 10:243-7

45 Cardoso C, Timsit S, Villard L, Khrestchatisky M, Fontes M, Colleaux L. Specific interaction between the XNP/ATR-X gene product and the SET domain of the human EZH2 protein. Hum Mol Genet 1998;7:679-84.

46 Shoichet SA, Hoffmann K, Menzel C, Trautmann U, Moser B, Hoeltzenbein M, Echenne B, Partington $M$, van Bokhoven H, Moraine C, Fryns JP, Chelly J, Rott HD, Ropers $\mathrm{HH}$, Kalscheuer M. Mutations in the ZNF41 gene are associated with cognitive deficits: identification of a new candidate for $X$ linked mental retardation. Am J Hum Genet 2003;73:1341-54. 